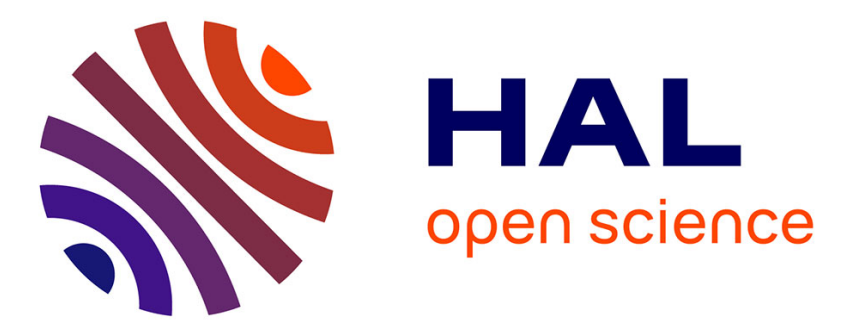

\title{
On my mind: thoughts about salience, context and figurative language from a second language perspective Istvan Kecskes
}

\section{To cite this version:}

Istvan Kecskes. On my mind: thoughts about salience, context and figurative language from a second language perspective. Second Language Research, 2006, 22 (2), pp.219-237. 10.1191/0267658306sr266ra . hal-00572099

\section{HAL Id: hal-00572099 \\ https://hal.science/hal-00572099}

Submitted on 1 Mar 2011

HAL is a multi-disciplinary open access archive for the deposit and dissemination of scientific research documents, whether they are published or not. The documents may come from teaching and research institutions in France or abroad, or from public or private research centers.
L'archive ouverte pluridisciplinaire HAL, est destinée au dépôt et à la diffusion de documents scientifiques de niveau recherche, publiés ou non, émanant des établissements d'enseignement et de recherche français ou étrangers, des laboratoires publics ou privés. 


\title{
On my mind: thoughts about salience, context and figurative language from a second language perspective
}

Istvan Kecskes State University of New York, Albany

\begin{abstract}
This article discusses three claims of the Graded Salience Hypothesis presented in Rachel Giora's book On our mind. It is argued that these claims may give second language researchers the chance to revise the way they think about word meaning, the literal meaning-figurative meaning dichotomy and the role of context in language processing. Giora's arguments are related to recent second language research and their relevance is explained through examples. There are also several suggestions made for further research.
\end{abstract}

Giora, R. 2003: On our mind: salience, context, and figurative language. Oxford: Oxford University Press. 259 pp. US\$55.00. ISBN 0-19-513616-0 (cloth).

\section{Introduction}

The impetus for this article was Rachel Giora's book On our mind: salience, context, and figurative language. Although it was not written specifically for applied linguists, we should be familiar with the content of this excellent book as it provides new information about how our mind works, and as the author's main arguments put into new perspective many things that we think we know about second language acquisition and bilingual development. What the book reveals about language comprehension and production derives from data mainly from monolinguals. This is perfectly all right since the book addresses processes characterizing the functioning of the human mind regardless 
of how many languages it operates. It is our task, as applied linguists, to make sense of these findings in our own paradigm. What I intend to do in this article is to review the claims in Giora's book that I find especially important for applied linguists and to relate them to current approaches in the field.

The book consists of nine well-organized chapters. In her Prologue, Giora offers some interesting examples of how our salience-bound mind works and describes the interactionist and modular view of language processing positing the Graded Salience Hypothesis (GSH) as an alternative. The main claim of the GSH is that stored information is superior to unstored information such as novel information or information inferable from context (Giora, 2003: 15). As a consequence, salient meanings of lexical units (e.g. conventional, frequent, familiar and prototypical) are processed automatically, irrespective of contextual information and strength of bias. Although context effects may be fast, they run in parallel and do not interact with lexical processes initially (Giora, 2003: 24). Chapters 2 and 3 discuss the notion of salience, its interplay with context, and how salient meanings affect ambiguity resolution. Chapters 4, 5 and 6 relate salience to irony, metaphors, idioms and jokes. Chapter 7 analyses the role of salience in aesthetic novelty. Chapter 8 addresses the conflicting findings on literal and figurative language in terms of the GSH. Chapter 9 is devoted to suggestions about possible further research and applications of the GSH. The author makes three claims that may be of special interest to applied linguists and second language researchers:

- Salient meanings are privileged meanings stored in the mind of individuals at a given time in a given speech community.

- Salient meanings can be either literal or figurative or both.

- In language processing, the meaning we first attend to is the salient meaning of lexical units in the utterance, regardless of contextual bias. Salient meanings are first accessed automatically and are then revised in the case of a mismatch with context.

\section{Privileged meaning}

The main argument of the book is that knowledge of salient meanings plays a primary role in the process of using and comprehending language. Giora claims that "privileged meanings, meanings foremost on 
our mind, affect comprehension and production primarily, regardless of context or literality' (Giora, 2003: 103). This means that salience refers to the most probable out of all possible interpretations of a lexical unit. The most salient meaning of a specific word, expression or utterance is the most conventional, frequent, familiar or prototypical interpretation. For instance, at the present time, the most probable interpretation of the word gay is 'homosexual' rather than 'merry' or 'lively'.

Words usually have multiple meanings, and some of these meanings are more accessible than others because we ascribe greater cognitive priority in our mental lexicon to some meanings over the rest. This sounds acceptable. But why is this so? What determines whether a particular meaning of a lexical unit receives priority or not in the mental lexicon? Why is it that the most salient meaning today of the word cool is not 'moderately cold', which is given as the primary meaning (1) in the dictionary (Morris, 1976: 292) but rather 'excellent, first-rate', which is given as meaning (8) marked as 'slang'? Why is it that out of 30 native-speaker respondents the majority considered 'stop kidding' as the most salient meaning of the expression get out of here rather than the literal meaning of the lexical unit (Kecskes, 2002: 130)? The answer to these questions seems relatively simple: these meanings are more salient because of prior experience and prior encounters with the word in relatively similar and typical contexts. These examples show us two things:

- salience is based on prior knowledge and experience, and thus it is a function of degree of familiarity; and

- salience is dynamic, and ready to change if use, environment, society and speakers change.

What relevance does this have to second language acquisition? Different experience results in different salience, and second language (L2) acquisition differs from first language (L1) acquisition. Consequently, what is salient for individuals belonging to the target language community will not necessarily be salient for the 'newcomers', the L2 learners. When acquiring and/or using another language, learners do two things. First, they rely on prior knowledge that is the knowledge of the first language and the socio-cultural background knowledge that the L1 is based upon. Second, they also give 
priority to certain meanings they encounter in the target language. So the primary meaning that emerges in the mind of an L2 learner as the most salient meaning of a lexical unit in the target language is the result of experience with two languages and cultures. Consequently, it may significantly differ from what the native speakers of that language consider as the most salient meaning of that particular lexical item or expression. This may cause misunderstandings in communication. The following conversation between a Korean student and a clerk in a human resource office illustrates this point:

1) Student: I would like you to help me with filling in this form.

Clerk: Come again..?

Student: Why should I? I am here now.

For the Korean student, the most salient meaning of the utterance come again was its literal meaning, while the native speaker used it in its figurative sense. Context hardly helped the student interpret the expression properly.

It seems fair to say that in order for non-native speakers to use the target language appropriately they are expected not only to develop the same or similar salience for lexical items and expressions that native speakers have but also follow the changes in salience as the target language is adjusted to the socio-cultural changes in the given language community. Is this not too much to expect of the language learner? Yes, it is. So here is one more reason why native-like competence is utopian and, in this respect, the interlanguage theory needs revision. No two native-like competencies in one body seem to be possible. This is confirmed by research on bilingualism and multicompetence. Grosjean (1989) argued that 'a bilingual is not two monolinguals in one body.' Discussing multicompetence Cook (1997) concluded that L2 users process language differently, and they have different knowledge of both their first and their second languages. Analysing the results of a longitudinal experiment, Kecskes and Papp (2000) pointed out that the bidirectional influence between the $\mathrm{L} 1$ and $\mathrm{L} 2$ results in a language use that is not exactly the same as the language use of monolinguals of either language. This is because while the languages are kept separate, thoughts originating in one and the same conceptual system are fed into two different language channels. 
However, we should not forget one thing. For non-native speakers to develop relatively the same salient meanings as those of native speakers is not a question of ability. Theoretically, L2 speakers can achieve this. What they are not able to do, however, is to go through the same or similar linguistic and socio-cultural experience that the native speakers go through, and which results in the salient meanings these native speakers have encoded in their minds. When native and non-native speakers were asked about the most salient meaning of the expression welcome aboard, the vast majority of native speakers referred to the same 'standard context' in which the situation-bound utterance is used (greeting a new employee), while the non-native speakers gave a variety of answers depending on their concrete experience (Kecskes, 2001: 253).

What becomes salient in the mind depends on conventions, familiarity and frequency of encounters (Giora, 2003), e.g. linguistic and socio-cultural experience. Research shows that what is carved in the mind is difficult to erase. Barro et al. (1993: 56) are right when they say that an advanced non-native speaker cannot be expected 'simply to abandon his/her own cultural world'. Similarly, as Adamson (1988) has pointed out, non-native speakers are often reluctant to accept and share the values, beliefs and presuppositions of an L2 community even if they have lived there for a long period of time and speak the language quite well. This fact usually has a profound effect on how salience develops in the mind of L2 learners. The dual language seems to be a far more complex system than the interlanguage theory suggests, and further investigation into the interplay of conceptual and linguistic levels is needed. The problem with the interlanguage hypothesis is that it focuses on linguistic and socio-cultural aspects of language development and use, while almost completely ignoring the conceptual aspects that are relevant to the mental representations of the linguistic system. The interlanguage approach is about the emerging second language, rather than about a unique symbiosis of two languages, a 'dual' language, as it is affected by the dynamic nature and bi-directionality of transfer, as well as by conceptual blending (Kecskes and Papp, 2000; Kecskes and Cuenca, 2005). The final goal of interlanguage development is native-like competence. Such a development is possible only if we accept the emergence of a new, additional conceptual system that is proper to the new language. Switching between two languages presupposes a switching between two conceptual systems. 
Such a hypothesis, however, contradicts to recent findings in bi- and multilingual research that have resulted in strong claims being made for a common underlying conceptual system (e.g. Grosjean, 1989; Paradis, 1995) that is incorporated by a dual language system (Kecskes and Papp, 2000).

\section{Literal or figurative?}

Salient meaning encodes standard context in which the given lexical item repeatedly occurs, on which we build our expectations about what may or may not happen, and on which our ability to understand and predict how the world around us works is based (see Violi, 2000). The more encounters we have with this coded meaning, the more familiar the situation(s) in which it occurs become. Factors such as frequency, familiarity and prototypicality play a decisive role in shaping the status of possible meanings and determine which one/ones become/s the most privileged of all possible meanings of a lexical unit.

An important claim of the GSH is that the most salient meaning is not always the literal meaning. Giora (2003: 33) defines 'literal meaning' as follows: 'Literal meaning refers to what is denoted by individual words, as well as to what is said by the compositional meaning of the sentence made up of these words intended nonfiguratively.' The most salient meaning(s) of a lexical unit can be either literal or figurative or sometimes even both. For instance, in the case of the expression give me a break or the word patronize both the literal meaning and figurative meaning can be considered salient. Giora argues that 'cognitively prominent salient meanings rather than literal meanings play the most important role in comprehension and production of language.' The GSH requires that the standard pragmatic model be therefore revised: instead of postulating the priority of literal meaning, the priority of salient (e.g. conventional, familiar, frequent, prototypical) meaning should be postulated (Giora, 1997). Consequently, it is not the figurative vs. literal split that matters, but the salient vs. non-salient continuum that really counts when processing the meaning of words or utterances.

The literal vs. figurative split has some psychological reality in the mind of native speakers, although this dichotomy has been problematic because native speakers often tend to identify literal meaning with the 
most frequent and familiar meaning of a lexical unit. The traditional linguistic approach claims that in most people's minds it is the literal meaning from which all other meanings derive (see Gibbs, 2002). The belief about the primacy of the literal meaning is so strong that not everyone notices when there is a shift in the semantic structure of a word, and what was once the most familiar, most frequent and most conventionalized of all possible senses gives way to another sense that takes over as the most salient sense but never as the literal meaning.

The following example may shed some light on this phenomenon: I had scheduled a meeting with one of my doctoral students who is a native speaker of English. She was late. When she entered my office, she said Hello, and gave the following explanation:

2) Sorry. I was held up at a gas station. Not literally though.

The explanation of the student raises the question: Why did she find it important to add Not literally though after the use of the lexical unit hold up? Why did she think that her words could have been interpreted incorrectly? Was it because she knew I was a non-native speaker? Not really. I confronted her with these questions. She said that she did not want me to think that there was actually a hold-up at the gas station. She actually thought that the literal meaning of the verb hold up was 'rob', which is clearly the figurative meaning, but which appears to be more salient for the native speaker than the literal meaning 'stop, prevent from doing something', because the verb hold up may be used more frequently in that figurative sense. According to The American Heritage Dictionary of the English Language (Morris, 1976: 628), the lexical entry hold up has the following readings:

1. to prevent from falling; to support,

2. to present for exhibit; to show,

3. to last; to stand up; to endure,

4. to stop or interrupt; to delay,

5. to rob.

So why was this confusion in the mind of this native speaker of American English? It is likely that what happened was that she equated the most frequent and familiar meaning, that is, the most salient meaning, with the literal meaning. 
What is important in the example above is that there must have been a shift in lexical representation, which may not have led to a shift in conceptual representation. This fact also confirms the need to differentiate between a lexical level and conceptual level of interpretation, which is not common in present-day second language acquisition theories (see Abel, 2003). The literal vs. figurative dichotomy makes sense for language analysis, but not for language processing, where it cannot be claimed that the literal is always processed before the figurative.

Where does this leave non-native speakers? They are expected to be up-to-date not only in meaning use but also in meaning shift that occurs in the target language. This is an unreasonable expectation. The GSH demonstrates the critical split between native speakers and non-native speakers in figurative language processing. Actually, this is a part of second language research where the GSH has already started to be applied. Recent studies on idioms and prefabricated pragmatic units use the GSH to demonstrate the difference between native speakers and non-native speakers in figurative language processing (e.g. Kecskes, 2001; 2004b; Bortfeld, 2002; Abel, 2003; Bortfeld, 2003; Cieślicka, forthcoming). These all concluded that, based on their differences in language acquisition, native speakers tend to take a holistic view toward idioms and consider their figurative meaning salient, while non-native speakers use an analytic approach toward idioms and usually take their literal meaning as salient. Abel (2003) found that nonnative speakers showed a general tendency to judge idioms as being decomposable, whereas native speakers more often judged them as being non-decomposable. A decompositional idiom is an idiom whose individual components contribute to its figurative meaning. Idioms whose individual constituents do not make such a contribution are nondecomposable. Abel's findings also showed that for native speakers the figurative meaning of an idiom is highly salient, which presupposes an idiom entry in the mental lexicon, whereas for non-native speakers it is less salient, which points to the fact that they rely on constituent analysis rather than on a developed separate entry.

In Bortfeld's (2003) experiments, subjects classified idioms from three languages according to their figurative meanings. Response times and error rates indicated that participants were able to interpret unfamiliar (e.g. other languages') idioms depending largely on the degree to which 
they were analysable, and that different forms of processing were used both within and between languages depending on this analysability.

Based on her findings, Cieślicka (forthcoming) advanced the proposition that literal meanings of idiom constituents enjoy processing priority over their figurative interpretations. Understanding L2 idioms entails an obligatory computation of the literal meanings of idiom constituent words, even if these idioms are embedded in a rich figurative context and if their idiomatic interpretation is well known to L2 learners. The literal salience model of L2 idiom comprehension proposed by Cieślicka ascribes a higher salience status to literal meanings, regardless of whether an L2 idiom is familiar to the learner or not, and regardless of contextual bias. Predictions of the model are thus in line with what the Graded Salience Hypothesis postulates for unfamiliar, or novel L1, figurative expressions.

Kecskes's analysis of a special type of idioms called 'situationbound utterances' (SBUs) is in accordance with the findings of other studies discussed above. While processing SBUs, his non-native speaker subjects used an analytic approach and usually identified the literal meaning of pragmatic units as most salient. Kecskes (2001; 2002) argued that salience is culture-specific and non-native speakers cannot be expected to approach figurative speech the way native speakers do because of their different linguistic and cultural experience.

L2 learners, especially those who have studied the L2 in an instructional environment, are usually much more familiar with the literal meanings of lexical units than with their figurative meanings. This is mainly due to the bottom-up approach to instruction that is based on the belief that instruction should follow a path from the easier to the more complex. Literal meaning has been considered less complex because this is the level at which lexical equivalency works. Figurative meaning, however, is rooted in the experience of the native speakers that is usually remote for the L2 learners. It is easy to find a lexical equivalent in many languages for the English word hit at the literal level such as 'hit my hand against the wall', or 'hit the target'. However, this is not the case with its figurative use: for instance, 'hit the road' or 'that really hit the spot'. Languages may have much lexical equivalency at the literal level but much less at the metaphorical, figurative level. The problem of L2 learners is that they usually consider the literal meaning of a L2 lexical unit as salient because in their L2 use that is the most familiar and frequent one. 


\section{Salience and context}

The most important contribution of the GSH to our understanding of language comprehension and production is its explanation of the interplay of coded meaning and contextual information in shaping actual communicative meaning. This has always been one of the major issues of language processing research. The idea of the priority of context and selective compliance with contextual information has dominated theoretical and applied linguistics, sociolinguistics, pragmatics and language teaching research for decades. Second language acquisition research is not an exception. It has usually worked with the traditional mode of analysis and has considered context the most decisive element of L2 processing, vocabulary acquisition and L2 reading (e.g. Nation and Coady, 1988; Hang, 1995; Dycus, 1997; Engelbart and Theuerkauf, 1999; Fraser, 1999). The analysis and application of GSH can help applied linguists put the dynamic relation of lexical units and contexts into a new perspective.

The GSH is a psycholinguistic approach, so it is important to review its place among the other available views that describe the relationship of context and lexical units.

\section{The psycholinguistic view}

The traditional interactionist, direct access view assumes that a strong context governs language processing and, thus, significantly affects lexical processes very early on. According to Gibbs (2002: 459), the direct access approach claims that listeners need not automatically analyse the complete literal meanings of linguistic expressions before accessing pragmatic knowledge to figure out what speakers mean to communicate. An alternative to the direct access view is the modular view, which presupposes that there are two distinct mechanisms: one bottom-up, sensitive to linguistic information, and another top-down, sensitive to contextual knowledge (both linguistic and extralinguistic). During processing, all meanings of a word are activated upon encounter. At times, the output of the linguistic module would cohere with contextual information, while on another occasions it would not, and would therefore require further inferential processes.

The GSH, which is considered a third alternative, claims, like the modular view, that there are two distinct mechanisms running parallel: an 
exhaustive but salience-sensitive mechanism that is receptive to linguistic information but impervious to context effects; and a predictive, integrative mechanism that is sensitive to linguistic and non-linguistic contextual information and interacts with lexical outputs. However, unlike the modular view (according to which 'the lexicon proposes and context disposes'; see Bates, 1999), the GSH assumes that the modular, lexical access mechanism is ordered: more salient meanings - coded meanings foremost on our mind due to conventionality, familiarity or frequency - are accessed faster than and reach sufficient levels of activation before less salient ones. And the context does not always dispose, depending on the role of the so-called irrelevant meanings in shaping the final interpretation (Giora, 2003). Gibbs (1994: 89-90) found that intended meaning of conventional utterances (idioms and indirect requests) is processed without any analysis of the sentence's literal meaning. In Giora's interpretation, these findings demonstrate the effect of meaning salience rather than attest to context effects because the most salient meaning of idioms and conventionalized indirect requests (for instance, 'Why don't you sit down?') is their non-literal meaning rather than their literal meaning.

Giora (2003: 11) gives a convincing example to show the interplay of lexical salience and context. In a discourse about computers, the computer appliance meaning of the word mouse would be expected to be the first to occur to the participants. This demonstrates that a highly predictive context may avail meanings on its own accord very early on. Giora, however, argues that context would not penetrate lexical access. Although it has a predictive role that may speed up derivation of appropriate meaning, the context would not obstruct inappropriate, coded meanings upon encounter of the lexical stimulus. So a novice learning how to use computer software may activate the literal meaning of mouse since to him or her that sense is more accessible than the appropriate one.

\section{Hierarchy of utterance interpretation}

As a result of the latest psycholinguistic research, there has emerged a view that considers utterance interpretation hierarchical. According to this, utterance interpretation starts with the lexical meaning of the word 
or pragmatic unit. If it does not lead to the relevant interpretation, then the immediate context comes into play. If this does not result in a pragmatically appropriate interpretation either, the context should be extended (see Bierwisch, 1997; Giora, 1997; Bibok and Németh T., 2001). The hierarchy of interpretation looks like this:

Lexical interpretation $\rightarrow$ Immediate context $\rightarrow$ Extended context

This approach accords with the two-level semantic (lexical semantics vs. conceptual semantics) theory (see Bierwisch, 1996; 1997) and the relevance theory of Sperber and Wilson (1995). Several researchers have come to support this hierarchy of utterance interpretation although they took different paths. While Giora $(1997 ; 2003)$ called this interpretation the 'Graded Salience Hypothesis', Bibok and Németh T. (2001) chose a different route via the principle of relevance, which states that 'human cognition tends to be geared to the maximization of relevance' (Sperber and Wilson, 1995: 260). This means that in communication we want to achieve more cognitive effects with less processing effort (see Wray, 2002). Consequently, processing should start with the most obvious and most salient meaning of lexical units making up the utterance. However, this meaning is either relevant to the given context or not. So relevance and salience are not the same, although sometimes what is salient is also relevant.

Supporters of the two-level semantic theory, relevance theory and GSH approach all agree with the hierarchy of interpretation. The difference is in their approach to the question of whether all possible meanings of a lexical unit are activated in the first phase of processing or only the most salient one (ones). Examining the contextual behaviour of ambiguous words, Gibbs (1996: 33) came to the conclusion that people momentarily activate all the meanings of an ambiguous word, with context then working to clarify its meaning. Context becomes operative only at a post-access stage, guiding the selection of the contextually relevant meaning of the ambiguous word. Gibbs and other cognitive linguists (see Bierwisch, 1997; Bibok and Németh T., 2001; Kövecses, 1993; Sperber and Wilson, 1995) may not be right when they say that all meanings of an ambiguous word are activated at the same time and context selects the right one. Or, in other words, the underspecified word meaning becomes specified by the context, as the supporters of the two-level semantics claim (see Bierwisch, 1997; Bibok and Németh T., 2001). 
The GSH maintains the opposite of this view: not all meanings, but only the most salient one(s) is (are) activated in the first phase of processing.

\section{The sociolinguistic view}

How does salient meaning relate to the internal interpretation of context and the cognitive theory of cultural meaning (Strauss and Quinn, 1997; Gee, 1999)? Words and pragmatic units can create their own contexts because they represent cultural models, standard contexts that have psychological reality for the socio-cultural group that considers them as reflections of reality. This derives from the unique reciprocity between language and reality. Language does two things simultaneously: it reflects reality (the way things are), and constructs reality to be a certain way. Gee (1999: 82) argued that 'reciprocity' is a good term to describe this property of language but 'reflexivity' is a more commonly used term because language and context are like two mirrors that face each other and 'constantly and endlessly reflect their own images back and forth between each other.'

Emphasizing that lexical units encode prior contexts of their use, the GSH offers psycholinguistic support to the sociolinguistic 'movement' that started with Gumperz (1982), who said that utterances somehow carry with them their own context or project the context. Referring to Gumperz's work, Levinson (2002) argued that the message vs. context opposition is false because the message can carry with it or forecast the context. Researchers, however, seem to hang on to the opposition because they focus on the foreground or message content, and it is the background that tends to project the context. Analysing the relationship of situation-bound utterances and context, Kecskes (2002; 2004a) concluded that actual contextual meaning is the result of a 'confrontation' between the activated world knowledge represented by the actual context and prior standard contexts encoded in the lexical units the speakers have chosen to use. This unique, two-way and dynamic relation of present and past contexts makes discourse as vivid and expressive as it is. It also confirms what Gumperz (1982; 1992) has claimed: social situations partially determine the choice of code, and yet that code-choice can partially determine situations.

Gumperz speaks about utterances, and the GSH focuses on lexical units: words and expressions. This, however, does not change the fact 
that there are no meanings that are context free, since each lexical item or pragmatic unit is always implicitly indexed to a standard context of reference. Lexical and pragmatic units encode the history of their prior contextual use. Salient meaning emerges as the most conventional, familiar and frequent out of this prior use. Actual context kicks in as a regulator when there is discrepancy between the coded standard context and the actual context. In this regulatory process, it is the actual context that has the final word. As Giora (2003: 147) claims, context becomes effective post-lexically, either retaining contextually appropriate meanings, allowing retrieval of less salient meanings or suppressing inappropriate meanings that interfere with the interpretation process.

\section{Dynamism of the interplay of lexical units and context}

Adopting this perspective significantly changes the traditional mode of analysis that considers context as selecting the relevant features and making the use of any given word appropriate, or inappropriate, in that context (see Violi, 2000). The GSH supports an approach that emphasizes the dynamism of the interplay of lexical units and context. According to this view, when language is used, speakers both create context and situations (make things meaningful in certain ways and not others) and fit, adjust and adapt language to these ongoing contexts and situations (see Gee, 1999). These contexts and situations are regularly recreated in a relatively similar way, and may be institutionalized and/or routinized, and as a consequence they can remain extent for a shorter or longer time in history because of the interactional needs that created them. Gee (1999) argued that in child language acquisition this process can be demonstrated very well because children learn how to fit their language to the context and situations primarily created by others in their socio-cultural groups. At the same time, children learn how certain forms of language can create and transform such context and situations.

Violi (2000) claimed that it is exactly standard contexts that linguistic meanings allude to. The relative stability of word meaning is based on the underlying regularity of their contexts of reference. However, it is important to emphasize that this relative stability is brought about by events that are only relatively similar. No two events can be exactly the same. When we talk about repeated events, what we really refer to is the similarity of 
the frame (see Fillmore, 1976; Fillmore and Atkins, 1992). For instance, reserving seats in a restaurant, greeting neighbours, ordering a pizza, renewing car insurance and so forth are scenarios in our lives that are repeated with a certain regularity, but none of these events are exactly the same, because both the linguistic and extralinguistic context as well as the lexicalization of thoughts vary all the time. Violi argued that:

words force interpretations upon us and compel us to develop hypotheses about what a possible compatible context may be. Words, then, can be said to impose their own context on the situation at hand, rather than saying that their meanings are merely affected by the context in which they are uttered. (Violi, 2000: 119)

I do not agree fully with Violi, because she emphasizes only one-way of a two-way street. As explained above, the relationship of lexical unit and context demonstrates the dynamism of language use that occurs both diachronically and synchronically. The meaning of a lexical unit can create context and be created by it. This fact ensures the dynamism of communication from the interlocutors' perspective. Based on previous experiences, lexical and pragmatic units have builtin contexts that are activated when the given lexical item is used. The activated built-in context has to be matched to the extralinguistic context of the situation. If there is no match between the two, it may lead to miscommunication. The following example illustrates this point well. In class, one of my students started to cough. A non-native speaker student said to him: 'Bless you.' Everybody started to laugh. When the SBU was uttered, it brought a context with it, that is, created a context that did not match the actual context. People say 'Bless you' when someone sneezes and not when someone coughs. Speakers use lexical units thinking that these units will create the right context for their thoughts when they are properly associated with other lexical units according to the rules of grammar. This is where we can say that lexical units create context. However, the created context is expected to match the extralinguistic context.

\section{Various types of context}

The application of the GSH obliges second language researchers to rethink what is meant by 'context'. Does a lexical unit represent a certain type of context? How do several types of contexts relate to each other in the course of shaping meaning? 
Our mind exists simultaneously both in the head and in the world. So linguistic context is what is uttered (or written) 'out there' in the world by a speaker in a situation (situational context), and is matched ('internalized') to the conventionalized, standardized contexts represented by lexical units 'inside' our heads (prior knowledge). So the linguistic context is created on line. When we communicate we internalize the uttered (or written) linguistic context, that is, we bring it into our mind (see Gardenfors, 1997; Jackendoff, 2002; Rapaport, 2003). The essence of inferential communication is that what matters for understanding of the internalized context is not what the context actually is (illocutionary force) but what the hearer (processor) thinks the context is (perlocutionary force). Kecskes (2004a) argued that, in fact, two prior 'knowledges' (standardized, conventionalized contexts) are matched in an actual, 'out there' context (situation). One of the prior 'knowledges' is represented in the utterances of the producer (speaker) while the other prior knowledge is represented in the head of the processor (hearer) who matches the uttered contexts to his or her prior experience with same or similar contexts in a frame represented by the actual 'out there' situation. For second language researchers, intriguing questions for further investigation might be:

- What standardized, conventionalized context is encoded in a target language lexical unit in the mind of the L2 learner?

- How does existing conceptual information (e.g. the American concept of lunch) blend with new pieces of knowledge added through the lexical equivalent of the word in the target language (e.g. the Spanish concept of comida); and

- How does the newly emerging conceptual structure affect the process of learning words in aural and/or written contexts?

\section{Conclusions}

In sum, Giora's book provides new insights supported by empirical evidence that prompt the reader to revise his or her views about L2 language processing, vocabulary acquisition, pragmatics and reading. The book has much to offer to applied linguists. The Graded Salience Hypothesis is worth testing with non-native speakers. This work has already begun and has produced some interesting results (Abel, 2003; 
Bortfeld, 2002; 2003; Cieślicka, forthcoming). The investigation of salience in second language acquisition should allow us to understand how emerging new conceptual knowledge blends with existing L1based conceptual knowledge, resulting in the development of a new complex language system and modifications in the operation of the L1. The GSH may help us develop an intake theory that focuses not only on input and output as the interlanguage approach does, but that attempts to explain what happens in the mind of language learners as they process new input.

\section{References}

Abel, B. 2003: English idioms in the first language and second language lexicon: a dual representation approach. Second Language Research 19, 329-58.

Adamson, H.D. 1988: Variation theory and second language acquisition. Georgetown University Press.

Barro, A., Byram, M., Grimm, H.H., Morgan, C. and Roberts, C. 1993: Cultural studies for advanced language learners. In Graddol, D., Thompson, L. and Byram, M., editors, Language and culture. Multilingual Matters, 55-70.

Bates, E. 1999: On the nature and nurture of language. In Bizzi, E., Calissano, P. and Volterra, V., editors, Frontiere della biologia il cervello di homo sapiens [Frontiers of biology: the brain of homo sapiens]. Instituto della Enciclopedia Italiana, 241-65.

Bibok, K. and Németh T., E. 2001: How the lexicon and context interact in the meaning construction of utterances. In Németh T., E. and Bibok, K., editors, Pragmatics and the flexibility of word meaning. Elsevier, 289-321.

Bierwisch, M. 1997: Lexical information from a minimalist point of view. In Wilder, C., Gärtner, H.M. and Bierwisch, M., editors, The role of economy principles in linguistic theory. Studia grammatica 40. Akademie Verlag, 227-66.

Bortfeld, H. 2002: What native and non-native speakers' images for idioms tell us about figurative language. In Heredia, R. and Altarriba, J., editors, Bilingual Sentence Processing. North Holland/Elsevier, 275-95.

- 2003: Comprehending idioms cross-linguistically. Experimental Psychology 50, 1-15.

Cieślicka, A. in press: Literal salience in on-line processing of idiomatic expressions by L2 learners. Journal of Pragmatics.

Cook, V. 1997: Monolingual bias in second language acquisition research. Revista Canaria de Estudios Ingleses 34, 35-50. 
Dycus, D. 1997: Guessing word meaning from context: should we encourage It? Literacy Across Cultures. 1-2.

Engelbart, S. and Theuerkauf, B. 1999: Defining context within vocabulary acquisition. Language Teaching Research 3, 57-69.

Fillmore, C. 1976: The need for a frame semantics within linguistics. SMIL Skriptor, 5-29.

Fillmore, C. and Atkins, B. 1992: Toward a frame-based lexicon. The semantics of RISK and its neighbors. In Lehrer, A. and Kittay, E.F., editors, Frames, fields, and contrasts. Lawrence Erlbaum, 75-102.

Fraser, C.A. 1999: Lexical processing strategy use and vocabulary learning through reading. Studies in Second Language Acquisition 21, 225-41.

Gardenfors, P. 1997: Meanings as conceptual structures. In Carrier, M. and Machamer, P., editors, Mindscapes. University of Pittsburgh Press.

Gee, J.P. 1999: An introduction to discourse analysis. Routledge.

Gibbs Jr., R.W. 1994: The poetics of mind. Cambridge University Press.

— 1996: What's cognitive about cognitive linguistics. In Casad, E.H., editors, Cognitive linguistics in the redwoods: the expansion of a new paradigm in linguistics. Cognitive Linguistics Research, 6. Mouton de Gruyter, 27-53.

2002: A new look at literal meaning in understanding what is said and implicated. Journal of Pragmatics 34, 457-86.

Giora, R. 1997: Understanding figurative and literal language. The graded salience hypothesis. Cognitive Linguistics 7, 183-206.

2003: On our mind: salience, context and figurative language. Oxford University Press.

Grosjean, F. 1989: Neurolinguistics, beware! The bilingual is not two monolinguals in one person. Brain and Language 36, 3-15.

Gumperz, J. 1982: Discourse strategies. Cambridge University Press.

—_ 1992: Contextualization and understanding. In Duranti, A. and Goodwin, C., editors, Rethinking context: language as an interactive phenomenon. Cambridge University Press, 229-52.

Hang, S. 1995: The effects of a context-embedded approach to second-language vocabulary learning. System 23, 43-55.

Jackendoff, R. 2002: Foundations of Language. Oxford University Press.

Kecskes, I. 2001: The 'graded salience hypothesis' in second language acquisition. In Niemeier, S. and Puetz, M., editors, Applied cognitive linguistics. Mouton de Gruyter, 249-71.

- 2002: Situation-bound utterances in L1 and L2. Mouton de Gruyter. 2004a: Lexical merging, conceptual blending and cultural crossing. Intercultural Pragmatics 1, 1-21.

2004b: The role of salience in processing pragmatic units. Acta Linguistica Hungarica 51, 309-24.

Kecskes, I. and Papp, T. 2000: Foreign language and mother tongue. Lawrence Erlbaum. 
Kecskes, I. and Cuenca, I.M. 2005: Lexical choice as a reflection of conceptual fluency. International Journal of Bilingualism 9, 49-69.

Kövecses, Z. 1993: Minimal and full definition of meaning. In: Geiger, R.A. and Rudzka-Ostyn, B., editors, Conceptualization and mental processing in language. Mouton de Gruyter, 247-66.

Levinson, S.C. 2002: Contextualizing contextualization cues. In Eerdmans, S., Prevignano, C. and Thibault, P., editors, Language and interaction: discussions with John J. Gumperz. John Benjamins, 31-39.

Morris, W., editor 1976: The American heritage dictionary of the English language. Houghton Mifflin.

Nation, P. and Coady, J. 1988: Vocabulary and reading. In Carter, R. and McCarthy, M., editors, Vocabulary and language teaching. Longman.

Paradis, M., editor 1995: Aspects of bilingual aphasia. Pergamon.

Rapaport, W.J. 2003: What is the 'context' for contextual vocabulary acquisition? In Slezak, P.P., editor, Proceedings of the 4th Joint International Conference on Cognitive Science/7th Australasian Society for Cognitive Science Conference. ICCS/ASCS-2003. Volume 2. University of New South Wales, 547-52.

Sperber, D. and Wilson, D. 1995: Relevance: communication and cognition. Blackwell.

Strauss, C. and Quinn, N. 1997: A cognitive theory of cultural meaning. Cambridge University Press.

Violi, P. 2000: Prototypicality, typicality and context. In Albertazzi, L., editor, Meaning and cognition. John Benjamins, 103-23.

Wray, A. 2002: Formulaic language and the lexicon. Cambridge University Press. 